\title{
SISTEM PENDUKUNG KEPUTUSAN PEMILIHAN KUALITAS PRODUK UPS TERBAIK MENGGUNAKAN METODE TOPSIS DAN SAW
}

\author{
Dimas Fathulyaqin $^{1}$, Ucuk Darusalam ${ }^{2}$, Ira Diana Sholihati ${ }^{3}$ \\ Program Studi Sistem Informasi, Universitas Nasional \\ dimasfathulyaqin@gmail.com
}

Submitted June 11, 2021; Revised June 14, 2021; Accepted June 18, 2021

\begin{abstract}
Abstrak
Setiap perangkat elektronik membutuhkan catu daya yang baik agar perangkat elektronik tersebut dapat menyala sesuai kebutuhan. Banyak perangkat menggunakan energi listrik. Mulai dari perangkat laptop atau komputer, TV, AC, kulkas, handphone, lampu semua menggunakan tenaga listrik. Bahkan di setiap instansi atau perusahaan membutuhkan energi listrik agar aktivitas kerja menjadi lebih optimal. UPS (Uninterruptible Power Supply) sendiri sangat berguna untuk melindungi perangkat elektronik dari pemadaman listrik yang dapat terjadi sewaktu-waktu. Alat ini menyimpan energi listrik seperti baterai dan mengalirkannya kembali, sehingga perangkat seperti komputer tidak rusak. Dengan menggunakan perhitungan algoritma metode TOPSIS (Technique For Others Reference by Similarity to Ideal Solution) dan SAW (Simple Additive Weighting) dalam pengambilan keputusan kualitas UPS terbaik dari segi kualitas barang dengan memperhitungkan kualitas bobot dengan kriteria sebagai berikut: Harga, Kapasitas (VA), Kapasitas (Watt) dan Runtime pada 60W (min).
\end{abstract}

Kata Kunci : Elektronik, UPS, TOPSIS, SAW, Sistem Pengambilan Keputusan.

\begin{abstract}
Every electronic device requires a good power supply so it perform functionally needed. Many devices use electrical energy. Starting from a laptop or computer device, TV, AC, refrigerator, cellphone, lights all use electric power. Even in every agency or company requires electrical energy for work activities to be more optimal. UPS (Uninterruptible Power Supply) itself is very useful for protecting electronic devices from blackouts that can occur at any time. This tool stores electrical energy such as battery and re-flows it, so that devices such as computers are not damaged. By using the calculation algorithm method TOPSIS (Technique For Others Reference by Similarity to Ideal Solution) and SAW (Simple Additive Weighting) in making the best UPS quality decisions in terms of quality of goods by considering the quality of weight with the following criteria: Price, Capacity (VA), Capacity (Watts) and Runtime at $60 \mathrm{~W}$ ( $\mathrm{min}$ ).
\end{abstract}

Key Words : Electronic, UPS, TOPSIS, SAW, Decision Making System.

\section{PENDAHULUAN}

Pada zaman era globalisasi ini banyak yang memakai teknologi baik itu handphone, TV dan sebagainya. Seiring berkembang pesatnya teknologi, setiap orang memakai macam-macam teknologi dan teknologi membutuhkan daya listrik agar teknologi bisa di jalankan dengan baik dan optimal. Teknologi tidak bisa di pisahkan oleh masyarakat. Karena itu, pada umumnya setiap orang mempunyai teknologi yang membutuhkan tenaga listrik, tenaga listrik bisa di peroleh dengan tenaga listrik PLN (Perusahaan Listrik Negara). Jika PLN mati, biasanya masyarakat menggunakan daya listrik cadangan seperti Power Bank untuk mengisi daya teknologi dan ada juga UPS (Uninterruptible Power Supply). Sama seperti power bank, fungsi UPS itu sendiri yaitu menyimpan daya listrik cadangan agar perangkat elektronik ketika dalam keadaan mati total (blackout) tidak langsung mati, pentingnya teknologi UPS berfungsi untuk menjaga keadaan arus listrik dari perangkat. Contohnya yaitu 
komputer, jika komputer dalam keadaan mati secara mendadak maka akan merusak komponen pada komputer. Karena itu, dengan adanya UPS, perangkat komputer akan lebih terjaga. Pemadaman listrik atau blackout dapat mengakibatkan efek negatif pada segala industri dan instansi maupun bisnis, contoh kasus blackout yang ada di Indonesia yaitu "Pemadaman di wilayah Jakarta, Banten, dan Jawa Barat yang terjadi pada akhir pekan lalu berlangsung selama kurang lebih 8-18 jam. Padamnya listrik disebabkan oleh gangguan pada transmisi SUTET 500kV PLN di Jawa Barat. Kerugian dari pemadaman ini diperkirakan mencapai triliunan rupiah. Aktivitas industri seperti konveksi, transportasi online, dan SPBU terkena imbas besar dari peristiwa ini. Selain itu, pelayanan publik seperti MRT, commuter line, ATM, dan pintu tol juga turut dirugikan"[1].

Memilih UPS untuk kegiatan sehari-hari membutuhkan perhitungan yang tepat dan akurat, UPS pada jaman dahulu di kenal dengan Powersupply yang hanya mampu menstabilkan tegangan cadangan listrik, seiring dengan perkembangan zaman dan meningkatnya kebutuhan keamanan data dan peralatan elektronik, maka pengembang melakukan riset terhadap powersupply dengan menambahkan teknologi Inverter di dalam powersupply tersebut. Pada saat itulah mulai di temukan sebuah perangkat yang mampu memberikan daya listrik cadangan yang berasal dari sistem inverter (Mengubah arus DC/Baterai ke arus AC), saat terjadi gangguan padamnya listrik pada perangkat yang di cadangkan[2]. Banyak masyarakat yang tidak tahu dalam memilih produk UPS untuk kegiatan sehari-hari. Karena itu, penulisan ini akan menjelaskan perhitungan dan hasil output apa saja pada produk UPS agar dapat memilih produk UPS yang dapat di pakai dengan menghitung bobot dari UPS. Perhitungannya yaitu seperti: Harga,
Kapasitas Volt, Kapasitas Watt dan jumlah outlet. Pada umumnya masyarakat memilih UPS dengan melihat Volt (tegangan listrik) saja. Padahal penting juga untuk memperhitungkan harga dan kapasitas Volt dan Watt.

Untuk menghitung bobot pada UPS itu sendiri di perlukan perhitungan Algoritma yang tepat. Algoritma adalah perhitungan prosedur langkah demi langkah untuk menghasilkan output yang dicapai. Salah satu perhitungan yang mendukung proses pengambilan data untuk output dengan keputusan yaitu dengan menggunakan sistem pendukung keputusan (Decision Support System). Sistem pendukung keputusan adalah bagian dari sistem informasi berbasis komputer (termasuk sistem berbasis pengetahuan (manajemen pengetahuan) yang dipakai untuk mendukung pengambilan keputusan dalam suatu organisasi atau perusahaan [3]. Secara umum DSS(Decision Support System) yaitu sistem informasi yang berisi pengetahuan yang dipakai untuk pengambilan keputusan.

Menurut Moore and Chang tentang DSS yaitu "dapat digambarkan sebagai sistem yang berkemampuan mendukung analisis ad hoc data, dan pemodelan keputusan, berorientasi keputusan, orientasi perencanaan masa depan, dan digunakan pada saat-saat tidak biasa"[4], permasalahan dalam penelitian ini yaitu perhitungan dalam metode SAW (Simple Additive Weighting) dan TOPSIS (Technique For Others Reference by Similarity to Ideal Solution) tidak menghasilkan hasil atau output yang sama. Karena itu, penulisan ini menjelaskan tentang kedua metode tersebut untuk menjadi perbandingan agar mengetahui metode yang lebih akurat.

Perancangan DSS dengan perbandingan TOPSIS dan SAW dapat membantu dalam pemilihan perhitungan kualitas UPS, seperti contoh pada penulisan 
"Perbandingan Metode TOPSIS dan SAW Untuk Pemilihan Rumah Tinggal" [5] dan “ Sistem Pendukung Keputusan Penentuan Karyawan Kontrak Menjadi Karyawan Tetap Menggunakan Metode Topsis"[6]. Metode tersebut diharapkan dapat menentukan kualitas terbaik pada produk UPS. Karena itu, dalam penulisan ini akan di jelaskan sebagaimana kedua metode itu menghasilkan output yang akurat atau tidak. Mulai dari perhitungan sampai aplikasi TOPSIS dan penjelasannya. Dan perhitungan manual pada metode SAW.

\section{METODE PENELITIAN}

Pada penelitian ini penulis memaparkan Langkah-langkah metode yang digunakan untuk UPS yaitu dengan metode TOPSIS dan SAW.

\section{Metode TOPSIS (Technique for Order of} Preference by Similarity to Ideal Solution)

TOPSIS (Technique for Order Preference by Similarity to Ideal Solution) merupakan metode pengambilan keputusan multikriteria dimana alternatif terbaik memiliki jarak terpanjang dari solusi ideal negatif dan memiliki jarak terpendek dari solusi ideal positif [7]. Urutan prosedur TOPSIS adalah sebagai berikut[8]:

1. Euclidean Length of a vector[8]:

$$
r i j=\frac{\mathrm{xij} \sqrt{\sum \mathrm{xij}}}{2 a}
$$

Penjelasan:

$$
\begin{aligned}
& \mathrm{r} \mathrm{i} \mathrm{j} \mathrm{=} \mathrm{matriks} \mathrm{normalisasi} \\
& \mathrm{x} \mathrm{i} \mathrm{j} \mathrm{=} \mathrm{variabel} \mathrm{keputusan}
\end{aligned}
$$

2. Menghitung nilai dengan perhitungan ideal positif (Di+) dan ideal negatif (Di-)

$$
D i+=\sqrt{\sum(y i+-y i j) 2 n i}
$$

Penjelasan: $\mathrm{Di}+=$ yaitu jarak ideal positif yit = elemen ideal positif yij

$$
D i-=\sqrt{\sum(y i+-y i j) 2 n j}
$$

Penjelasan: Di- = yaitu jarak ideal negatif yi- = elemen ideal negatif $y i j$

\section{3. keputusan bobot normalisasi}

Variable normalisasi dikalikan dengan bobot dan akan menghasilkan bobot normalisasi dimana Yij merupakan variabelnya.

$$
Y i j=w j . r i j
$$

Penjelasan: variabel pada wj nilainya adalah positif untuk proses hitung keuntungan, sementara untuk cost bernilai negatif, variable $\mathrm{w}$ merupakan bobot kriteria.

\section{Metode SAW (Simple Additive Weighting)}

Metode SAW sering dikenal dengan istilah metode penjumlahan terbobot. Tujuan metode SAW (Simple Additive Weighting) yaitu untuk mencari hasil jumlah bobot.

$$
\begin{aligned}
& . r i j=\frac{\mathrm{xij}}{\max x i j} \\
& r i j=\frac{\min x i j}{x i j}
\end{aligned}
$$

Penjelasan: pada variable $\mathrm{R}$ yaitu merupakan hasil normalisasi sementara $\mathrm{X}$ yaitu nilai pada setiap kriteria.

$\mathrm{R}$ merupakan hasil normalisasi yang ada pada data alternatif:

$$
V i=\sum_{j=1}^{n} w j r i j
$$

Penjelasan: Untuk vi yaitu merupakan data pada alternatif, untuk $\mathrm{w}$ yaitu bobot untuk kriteria, $r$ merupakan hasil normalisasi. 


\section{HASIL DAN PEMBAHASAN}

\section{Implementasi Metode TOPSIS} (Technique for Order of Preference by Similarity to Ideal Solution) Untuk merk UPS

Untuk dapat mengetahui hasil dari perhitungan metode TOPSIS dibutuhkan variable kriteria(C) dan akan menghasilkan merk UPS yang terbaik, dalam penulisan ini terdapat empat kriteria yang merujuk pada data sekunder pada "Perancangan boost converter menggunakan kontrol proporsional integral (PI) sebagai suplai tegangan input inverter satu fasa untuk sistem uninterruptible power supply"[9], yaitu:

$$
\begin{array}{ll}
- & (\mathrm{C} 1)=\text { Harga } \\
\text { - } & (\mathrm{C} 2)=\text { Kapasitas (VA) } \\
\text { - } & (\mathrm{C} 3)=\text { Kapasitas (Watt) } \\
& (\mathrm{C} 4)=\text { Runtime at 60W ( min ) }
\end{array}
$$

Semua kriteria akan dibandingkan dengan cara memasukan nilai bobot kriteria setelah nilai telah di dapat. Lalu langkah selanjutnya yaitu dengan cara membandingkan masing-masing data alternatif untuk menghasilkan output rangking yang utama. Berikut contoh proses perhitungan TOPSIS.

\section{Penentuan Variabel dan Kriteria}

\begin{tabular}{|c|c|c|c|}
\hline \multirow[t]{3}{*}{ Watt) } & $600-700$ & \multirow[b]{2}{*}{ Besar } & \multirow[b]{2}{*}{0.8} \\
\hline & & & \\
\hline & $<600$ & Cukup & 0.7 \\
\hline \multirow{3}{*}{$\begin{array}{c}\mathrm{C} 4 \\
\text { (Runtime at } \\
60 \mathrm{~W})\end{array}$} & $>80 \mathrm{~min}$ & Sangat Lama & 0.9 \\
\hline & $40-50 \mathrm{~min}$ & Sedang & 0.8 \\
\hline & $<40 \min$ & Cukup & 0.7 \\
\hline
\end{tabular}

Tabel 1. Data Variabel Kriteria UPS Dengan Nilai

\begin{tabular}{cccc}
\hline Kriteria & Range & Keterangan & Nilai \\
\hline & $>1020000$ & Sangat Mahal & 0.9 \\
C1 & & & \\
\cline { 2 - 4 }$($ Harga $)$ & $990000-$ & & 0.8 \\
& 1020000 & Bagus & 0.7 \\
\cline { 2 - 4 } & $<990000$ & Cukup & 0.9 \\
C2 & $>1050$ & Sangat Besar & 0.8 \\
\cline { 2 - 4 }$($ Kapasitas \\
VA) & $900-1050$ & Besar & 0.7 \\
\cline { 2 - 4 } & $<900$ & Cukup & 0.9 \\
\hline $\begin{array}{c}\text { C3 } \\
\text { (Kapasitas }\end{array}$ & $>800$ & Sangat Besar & \\
\hline
\end{tabular}

Tabel 1 menunjukkan Variabel dan Kriteria UPS. Terdapat empat kriteria yaitu Harga, Kapasitas Volt, Kapasitas Watt dan runtime. Bobot dari range itu sendiri mempunyai tiga nilai dari yang terendah yaitu tujuh dan tertinggi yaitu sembilan.

Tabel 2. Data UPS Dengan Nilai Standar Awal

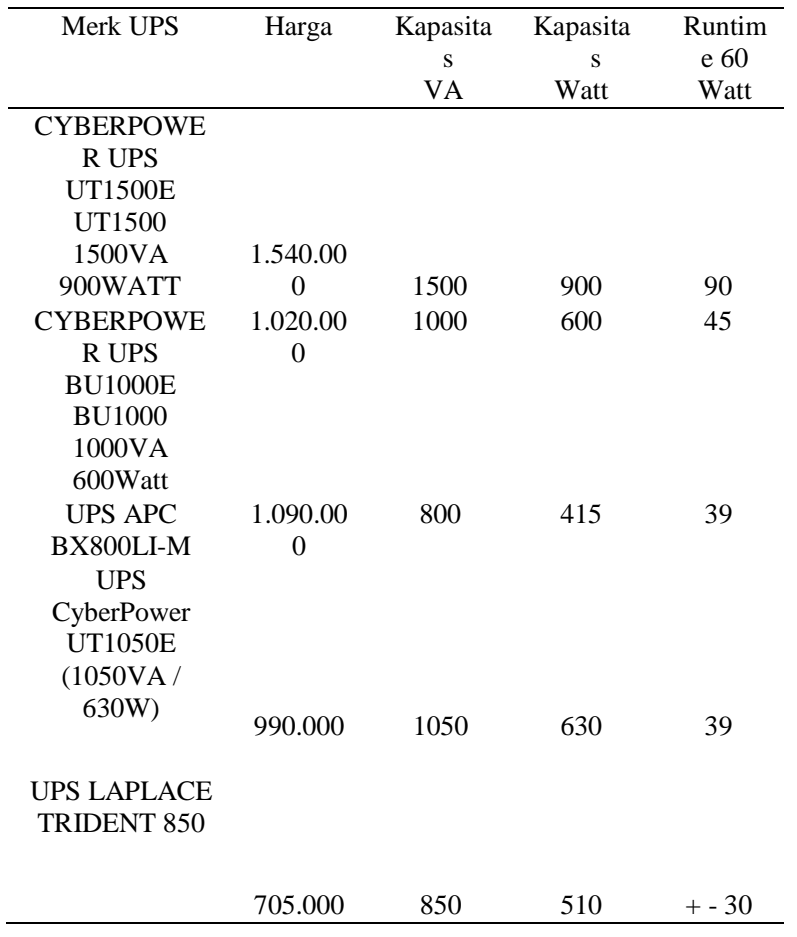

Tabel 2. menunjukan nilai dari kriteria yang telah ditentukan dari data UPS yang ada, table ini menjelaskan nilai yang akan di hitung dengan metode TOPSIS dan akan di konversi. 
Tabel 3. Konversi Data UPS ke Dalam Bentuk Nilai

\begin{tabular}{ccccc}
\hline Alternatif & C1 & C2 & C3 & C4 \\
\hline A1 & 0.9 & 0.9 & 0.9 & 0.9 \\
A2 & 0.8 & 0.8 & 0.8 & 0.8 \\
A3 & 0.9 & 0.7 & 0.7 & 0.7 \\
A4 & 0.8 & 0.8 & 0.8 & 0.7 \\
A5 & 0.7 & 0.7 & 0.7 & 0.7 \\
\hline
\end{tabular}

Tabel 3 merupakan hasil konversi data yang disesuaikan dengan nilai variabel pada tabel 1 dan tabel 2 berdasarkan bobot range pada tabel 1 .

Tabel 4. Varibel Bobot Pada Produk UPS

\begin{tabular}{ccc}
\hline Kode Kriteria & Kriteria & Bobot \\
\hline C1 & Harga & 3 \\
C2 & Kapasitas VA & 5 \\
C3 & Kapasitas Watt & 5 \\
C4 & Runtime 60 Watt & 3 \\
\hline
\end{tabular}

Dari bobot pada tabel 4 jika bobot nya adalah 3 maka bernilai cost dan jika bobot nya adalah 5 maka bernilai benefit. Benefit merupakan nilai tertinggi menjadi terbaik, sementara cost merupakan nilai terkecil menjadi terbaik.

\section{Perhitungan Metode TOPSIS}

1. Menentukan matriks ternormalisasi

Tabel 5. Matriks Hasil Normalisasi UPS

\begin{tabular}{ccccc}
\hline Alterna tif & C1 & C2 & C3 & C4 \\
& & & & \\
\hline A1 & 0.409 & 0.513 & 0.513 & 0.526 \\
A2 & 0.363 & 0.456 & 0.456 & 0.468 \\
A3 & 0.409 & 0.399 & 0.399 & 0.409 \\
A4 & 0.363 & 0.456 & 0.456 & 0.409 \\
& & & & \\
A5 & 0.318 & 0.399 & 0.399 & 0.409 \\
& & & & \\
\hline
\end{tabular}

Setelah itu menentukan perhitungan normalisasi terbobot, proses ini mekanismenya yaitu mengalikan setiap kolom pada setiap kriteria $\mathrm{W}=(3,5,5,3)$ maka hasilnya:

Tabel 6. Keputusan Normalisasi Terbobot pada UPS

\begin{tabular}{ccccc}
\hline $\begin{array}{c}\text { Alterna } \\
\text { tif }\end{array}$ & $\mathrm{C} 1$ & $\mathrm{C} 2$ & $\mathrm{C} 3$ & $\mathrm{C} 4$ \\
$\mathrm{~A} 1$ & 1.227 & 2.565 & 2.565 & 1.578 \\
$\mathrm{~A} 2$ & 1.089 & 2.28 & 2.28 & 1.404 \\
$\mathrm{~A} 3$ & 1.227 & 1.995 & 1.995 & 1.227 \\
$\mathrm{~A} 4$ & 1.089 & 2.28 & 2.28 & 1.227 \\
& & & & \\
$\mathrm{~A} 5$ & 0.954 & 1.995 & 1.995 & 1.227 \\
\hline
\end{tabular}

Tahap selanjutnya yaitu menentukan hasil nilai ideal positif dan ideal negatif dengan mencari nilai terendah(min) dan tertinggi(max), maka yang di dapat adalah: 
Tabel 7. Ideal Positif dan Ideal Negatif Produk UPS

\begin{tabular}{l|l|l|l|l}
\hline $\begin{array}{l}\text { Max } \\
\left(V_{j}^{+}\right)\end{array}$ & 1.227 & 2.565 & 2.565 & 1.578 \\
\hline $\begin{array}{l}\operatorname{Min}\left(V_{j}^{-}\right. \\
)\end{array}$ & 0.954 & 1.995 & 1.995 & 1.227 \\
\hline
\end{tabular}

Setelah itu hitung jarak alternatif seperti pada pada rumus 2 dan rumus 3 pada metode TOPSIS, maka hasilnya:

Tabel 8. Jarak Alternatif

\begin{tabular}{c|c|c|c|c|c}
\hline Di+ & 0.479 & 0.469 & 0.870 & 0.435 & 0.807 \\
\hline Di- & 0.807 & 0.469 & 0.351 & 0.559 & 0.479 \\
\hline
\end{tabular}

Setelah itu menghitung nilai pada data alternatif yang terdapat di rumus 7 metode topsis hasil akhir dari nilai TOPSIS adalah:

Tabel 9. Hasil Akhir TOPSIS

\begin{tabular}{cll}
\hline Rangking & \multicolumn{1}{c}{ Merk UPS } & Nilai \\
\hline 1 & $\begin{array}{l}\text { CYBERPOWER UPS } \\
\text { UT1500E UT1500 1500VA } \\
\text { 900WATT }\end{array}$ & 0.627 \\
& $\begin{array}{l}\text { UPS CyberPower UT1050E } \\
\text { (1050VA / 630W) }\end{array}$ & 0.562 \\
2 & $\begin{array}{l}\text { CYBERPOWER UPS } \\
\text { BU1000E BU1000VA }\end{array}$ & 0.5 \\
3 & $\begin{array}{l}\text { 600Watt } \\
\text { UPS LAPLACE TRIDENT }\end{array}$ & 0.372 \\
& 850 & 0.287 \\
5 & UPS APC BX800LI-M & \\
\hline
\end{tabular}

\section{Implementasi Metode SAW (Simple Additive Weighting)}

Hampir sama dengan metode TOPSIS dibutuhkan penentuan kriteria dan alternatif,.seperti pada tabel 2 pada metode TOPSIS, setelah itu dilakukan normalisasi paling besar dengan cara membagi nilai, jika nilai kriteria memiliki bobot cost maka dibagi nilai terendah jika nilai tertinggi maka dibagi nilai maksimal pada setiap kolom pada data alternatif, maka hasil normalisasi paling besar dan normalisasi paling kecil yaitu:

Normalisasi kriteria 1:

r51 $=705.000 / 1.540 .000=0.46$

$\mathrm{r} 41=705.000 / 990.000=0.71$

$\mathrm{r} 31=705.000 / 1.090 .000=0.64$

$\mathrm{r} 21=705.000 / 1.020 .000=0.69$

$\mathrm{r} 11=705.000 / 705.000=1$

Normalisasi kriteria 2:

$$
\begin{aligned}
& \mathrm{r} 12=800 / 1500=0.53 \\
& \mathrm{r} 22=850 / 1500=0.56 \\
& \mathrm{r} 32=1000 / 1500=0.67 \\
& \mathrm{r} 42=1050 / 1500=0.7 \\
& \mathrm{r} 52=1500 / 1500=1
\end{aligned}
$$

Normalisasi kriteria 3:

$$
\begin{aligned}
& \mathrm{r} 13=415 / 900=0.46 \\
& \mathrm{r} 23=510 / 900=0.56 \\
& \mathrm{r} 33=600 / 900=0.66 \\
& \mathrm{r} 43=630 / 900=0.7 \\
& \mathrm{r} 53=900 / 900=1
\end{aligned}
$$

Normalisasi kriteria 4

$$
\begin{aligned}
& \mathrm{r} 14=30 / 90=0.3 \\
& \mathrm{r} 24=30 / 45=0.66 \\
& \mathrm{r} 34=30 / 39=0.76 \\
& \mathrm{r} 44=30 / 39=0.76 \\
& \mathrm{r} 54=30 / 30=1
\end{aligned}
$$

Setelah itu disesuaikan baris dan kolom pada hasil normalisasi kriteria dan dijadikan table untuk di jadikan output pada hasil SAW.

Tabel 10. Hasil Normalisasi SAW

\begin{tabular}{llll}
\hline 1 & 0.53 & 0.46 & 0.3 \\
0.69 & 0.56 & 0.56 & 0.66 \\
0.64 & 0.67 & 0.66 & 0.76 \\
0.71 & 0.7 & 0.7 & 0.76 \\
0.46 & 1 & 1 & 1 \\
\hline
\end{tabular}

Setelah itu hasil normalisasi SAW di kali dengan bobot pada tabel 4 metode TOPSIS lalu hasil perkalian dijumlahkan begitu seterusnya pada setiap baris maka hasilnya adalah hasil akhir keputusan pada metode SAW: 
Tabel 11. Hasil Akhir SAW

\begin{tabular}{|c|c|c|}
\hline Rangking & Merk UPS & Nilai \\
\hline 1 & $\begin{array}{lr}\text { CYBERPOWER } & \text { UPS } \\
\text { UT1500E UT1500 } & 1500 \mathrm{VA} \\
\text { 900WATT }\end{array}$ & 0.885 \\
\hline 2 & $\begin{array}{l}\text { CYBERPOWER UPS } \\
\text { BU1000E BU1000 1000VA } \\
\text { 600Wattv }\end{array}$ & 0.2828 \\
\hline 3 & UPS APC BX800LI-M & 0.1085 \\
\hline 4 & UPS CyberPower UT1050E & 0.3058 \\
\hline 5 & $\begin{array}{l}\text { UPS LAPLACE TRIDENT } \\
850\end{array}$ & 0.1438 \\
\hline
\end{tabular}

\section{Analisa Metode TOPSIS dan SAW}

Hasil output pada metode topsis dapat dilihat dari perhitungan yang sudah di dapat, berikut table perbandingan antara table pada metode TOPSIS dan SAW:

\section{Tabel 12. Tabel Hasil Dari TOPSIS}

\begin{tabular}{cll}
\hline Rangking & \multicolumn{1}{c}{ Merk UPS } & Nilai \\
\hline 1 & CYBERPOWER & 0.627 \\
& UPS UT1500E & \\
& UT1500 \\
& 1500VA & \\
& 900 WATT & \\
& UPS & 0.562 \\
& CyberPower & \\
& UT1050E \\
& (1050VA / \\
& 630W) \\
& CYBERPOWER & 0.5 \\
& UPS BU1000E \\
& BU1000VA \\
& 600Watt \\
& UPS LAPLACE & 0.372 \\
4 & TRIDENT 850 \\
& UPS APC & 0.287 \\
5 & BX800LI-M & \\
\hline
\end{tabular}

Tabel 13. Tabel Hasil Dari SAW

\begin{tabular}{lll}
\hline Rangking & Merk UPS & Nilai \\
\hline 1 & CYBERPOWER & 0.885 \\
& UPS UT1500E & \\
& UT1500 & \\
& 1500VA & \\
& 900 WATT & \\
& CYBERPOWER & 0.2828 \\
& UPS BU1000E & \\
2 & BU1000 & \\
& 1000VA & \\
& 600Wattv & \\
3 & UPS APC & 0.1085 \\
& BX800LI-M & \\
4 & UPS & 0.3058 \\
4 & CyberPower & \\
& UT1050E & \\
5 & UPS LAPLACE & 0.1438 \\
& TRIDENT 850 & \\
\hline
\end{tabular}

Use Case Diagram

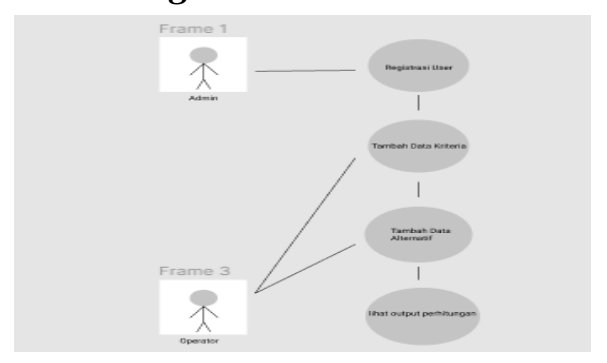

Gambar 2. Usecase Diagram Aplikasi

Diagram ini menjelaskan tentang dua peran dalam satu aplikasi, admin dan operator. Admin dapat mengakses penuh dalam aplikasi dari menambahkan data user dalam proses registrasi, menambah data kriteria, menambah data alternatif, dan melihat output perhitungan dalam metode topsis.

\section{Flowchart}

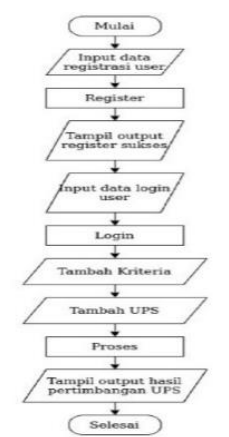

Gambar 3. Flowchart Aplikasi

Flowchart merupakan susunan atau diagram alur dari aplikasi, dimulai dari proses register lalu menampilkan data user, input data login lalu login sebagai admin, tambah kriteria lalu tambah data alternatif lalu di proses dan menampilkan output terakhir.

\section{Tampilan Sistem}

1. Halaman login

Sebelum melakukan proses perhitungan TOPSIS harus di lakukan proses log in yaitu memasukan username serta password yang telah di input pada database. 


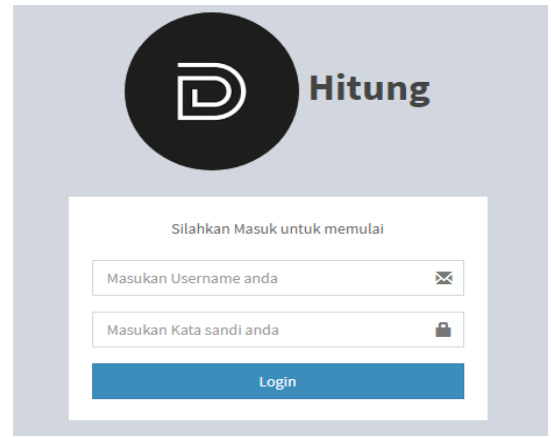

Gambar 4. Tampilan Login

\section{Halaman Utama}

Dalam halaman utama sebagai admin dapat melihat Riwayat atau history proses sistem yang telah dilakukan.

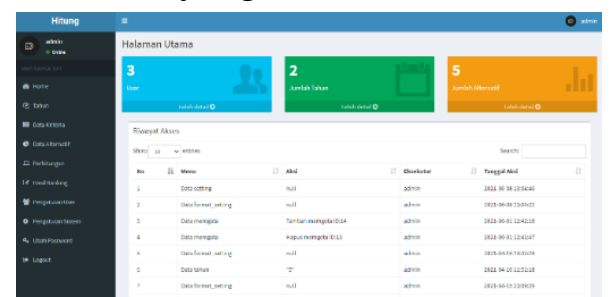

Gambar 5. Halaman Utama

\section{Halaman Data Kriteria}

Pada tampilan ini user bisa melihat data kriteria untuk menghapus, menambahkan dan edit data, kriteria merupakan salah satu bagian penting dalam proses perhitungan TOPSIS, disini kriterianya yaitu: Harga, Kapasitas Volt, Kapasitas Watt dan Runtime.

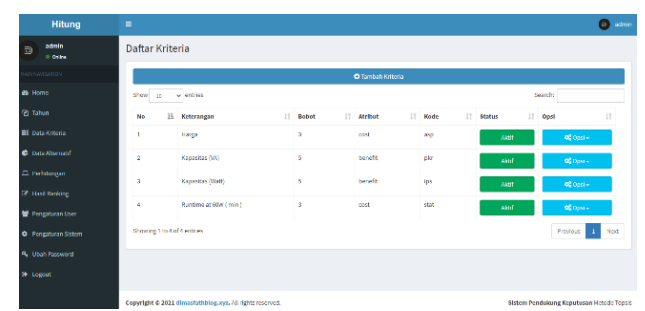

Gambar 6. Halaman Kriteria

\section{Halaman Data Alternatif}

User bisa menambahkan data alternatif seperti merk UPS yang akan ditambahkan.

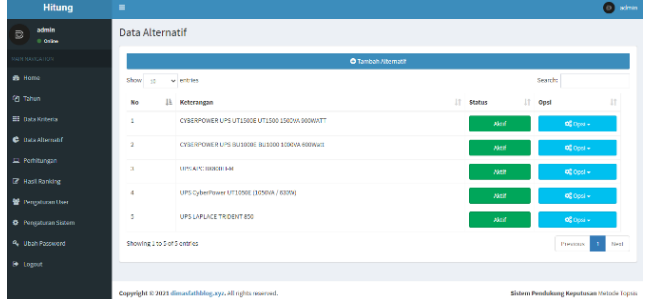

Gambar 7. Halaman Web Alternatif

5. Halaman Perhitungan

Admin dapat melihat data TOPSIS mulai dari proses normalisasi sampai tahap kedekatan relatif untuk di jadikan perhitungan output.

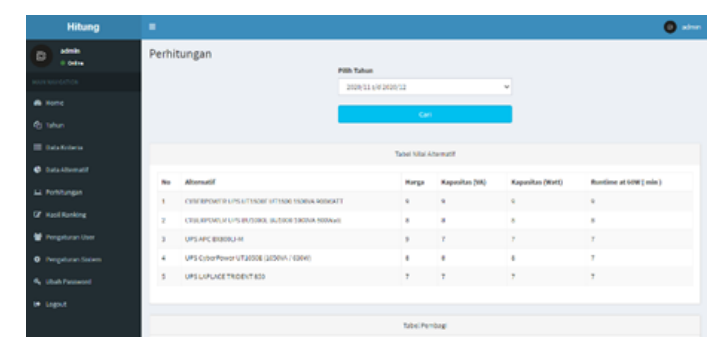

Gambar 8. Halaman Web Perhitungan

\section{Halaman Pengaturan User}

Di halaman ini, admin bisa melihat data user yang sudah di registrasi, pada halaman ini admin juga bisa edit, hapus dan tambah data user untuk menjadi operator(user) atau menjadi admin.

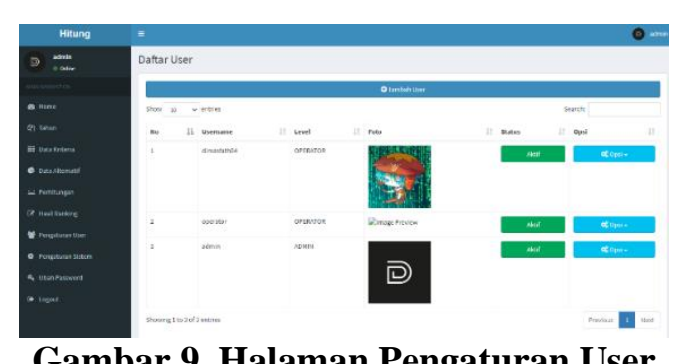

Gambar 9. Halaman Pengaturan User

\section{Halaman Hasil Ranking}

Pada halaman ini admin dapat melihat hasil rangking produk UPS dan memiliki hak akses untuk print data hasil output perhitungan TOPSIS. 


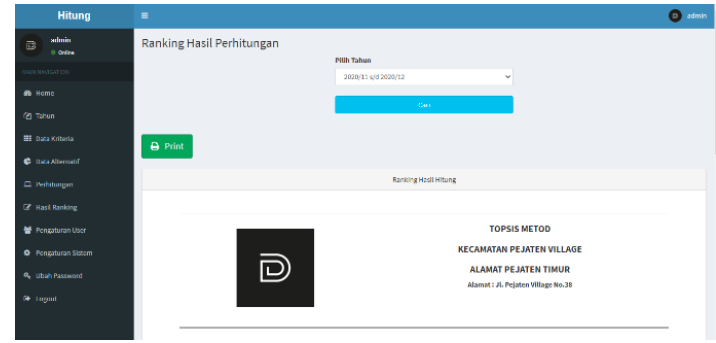

Gambar 10. Halaman Hasil Ranking

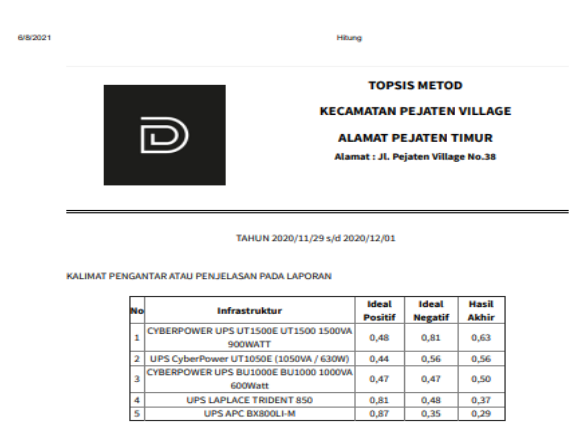

Gambar 11. Hasil Print PDF

\section{SIMPULAN}

Hasil penelitian dari pembanding antara metode TOPSIS dan SAW dapat disimpulkan bahwa kedua metode ini dapat mendukung keputusan yang tepat dalam pemilihan merk UPS terbaik, berikut kesimpulan dari pembanding:

a. Dalam pengujian sistem dapat dilihat bahwa dalam perhitungan metode TOPSIS dan metode SAW menghasilkan nilai yang berbeda pada perhitungan dari bobot, kriteria dan alternatif dengan nilai yang sama.

b. Dalam Analisa UPS dapat dikatakan perhitungan SAW cenderung akurat daripada perhitungan TOPSIS karena output dari perhitungan SAW memiliki nilai lebih tinggi dari hasil perhitungan TOPSIS, data alternatif terbaik adalah merk UPS CYBERPOWER UPS UT1500E UT1500 1500VA 900WATT di lihat dari kriteria Harga, Kapasitas Volt, Kapasitas Watt, dan Runtime. Hasil keduanya menunujukan bahwa UPS Cyberpower UT1500E adalah merk terbaik dan menjadi barang rekomendasi untuk di beli oleh pengguna.

c. Keunggulan dalam metode TOPSIS yaitu perhitungan yang secara detail dengan rumus yang lebih banyak, sementara keunggulan dari metode SAW yaitu perhitungan yang lebih akurat.

\section{DAFTAR PUSTAKA}

[1] J. N. G. B. H. Putra, A. Nugroho, A. Naryoso, "Komunikasi Strategis Untuk Pengelolaan Krisis Publisitas Tentang Pemadaman Listrik PT.PLN (PERSERO) Distribusi Jawa Tengah DIY," vol. 3 No.3, no. Interaksi Online, 2015.

[2] C. Pratiwi, Rani Ramadhani Eka, "Pengaruh Proses Pengisian (Charging) Baterai Terhadap Efisiensi UPS (Uninteruptable Power Supply) Di PT. Pupuk Sriwidjaja Area 2B Palembang," no. Undergraduate Thesis, Universitas Sriwijaya, 2019.

[3] A. F. Adzan. M., "Sistem Pendukung Keputusan Pemilihan Laptop Dengan Metode Analytical Hierarki Process(AHP) Berbasis Web Mobile," vol. 6 No 1, no. SINTAK, 2019.

[4] Sunarti, "Perbandingan Metode TOPSIS dan SAW Untuk Pemilihan Rumah Tinggal," vol. 3 No.1, no. JOINS (Journal of Information System), pp. 69-79, 2018.

[5] K. Zeni Muhamad Noer, "Aplikasi Decision Support System Komposisi Pakan Untuk Penggemukan Sapi Potong," vol. 6 No. 1, no. JUTEKIN, 2018.

[6] S. Mallu, "Sistem Pendukung Keputusan Penentuan Karyawan Kontrak Menjadi Karyawan Tetap Menggunakan Metode Topsis," vol. 1 No 2, no. JITTER, pp. 36-42, 
STRING (Satuan Tulisan Riset dan Inovasi Teknologi)

Vol. 6 No. 1 Agustus 2021

2015.

[7] S. S. Enok Tuti Alawiah, "Sistem Pendukung Keputusan Pembelian Vending Machine Dengan Metode TOPSIS Studi Kasus PT. KAI Commuter Jabodetabek," vol. 3 No 2, no. IJCIT, pp. 4-6, 2018.

[8] H. E. Wahyuni. S., Niska. D. Y., "Sistem Pendukung Keputusan Penentuan Siswa Berprestasi
p-ISSN: $2527-9661$

e-ISSN: 2549 - 2837

Menggunakan Metode TOPSIS pada SMA Sinar Husni," vol. 6 No 1, no. JUTI, pp. 46-51, 2019.

[9] I. Teguh Tri Arvianto, Endro Wahjono, "Perancangan boost converter menggunakan kontrol proporsional integral (PI) sebagai suplai tegangan input inverter satu fasa untuk sistem uninterruptible power supply," vol. 16 No. 2, no. TEKNIKA, 2020. 